\title{
Hepatitis E: state of the art
}

\author{
Harry Dalton \\ From $16^{\text {th }}$ International Symposium on HIV and Emerging Infectious Diseases \\ Marseille, France. 24-26 March 2010
}

Hepatitis E (HEV) has traditionally been thought to be a disease of developing countries. In this setting, HEV causes hepatitis in young adults. It is generally a selflimiting illness, with a good prognosis, except in pregnant women and patients with pre-existing chronic liver disease, in whom the mortality is $20 \%$ and $70 \%$ respectively.

Traditionally HEV was considered rare in developed countries, and confined to travellers returning from endemic areas. However, recent data has shown that locally acquired HEV infection is common in developed countries. Acute HEV infection in this setting is caused by HEV genotype 3 and appears to have a predilection for middle aged/elderly males. It has a significant morbidity (15\%) and carries an adverse prognosis in chronic liver disease. HEV infection is commonly misdiagnosed as drug-induced liver injury. The source and route of infection are currently uncertain, but evidence suggests that HEV genotype 3 is a porcine zoonosis, which can be transmitted via the human food chain.

Until very recently chronic HEV infection was thought not to occur. However studies from Europe have shown that HEV genotype 3 can cause chronic infection with rapidly progressive cirrhosis in patients with immunocompromise. This includes patients taking immunosuppressive therapy following solid organ transplantation and patients with HIV-1 infection (NEJM 2009; 361(10): 1025-7).

HEV IgG seroprevalence in developed countries is variable, with rates of $16 \%$ reported from the UK and SW France. These data indicate that HEV infection is either commonly subclinical, or commonly overlooked as a diagnostic possibility. However, the burden of HEV disease in both the developing and developed world is currently uncertain. The worldwide burden of chronic HEV infection may prove to be more considerable than

\footnotetext{
Consultant Gastroenterologist and Hon Senior Lecturer, Royal Cornwall
} Hospital \& Peninsula College of Medicine and Dentistry, Truro, UK previously thought likely, as countries where HEV is endemic also have a high seroprevalence of HIV.

Published: 11 May 2010

doi:10.1186/1742-4690-7-S1-I1

Cite this article as: Dalton: Hepatitis E: state of the art. Retrovirology 2010 7(Suppl 1):11.
Submit your next manuscript to BioMed Central and take full advantage of:

- Convenient online submission

- Thorough peer review

- No space constraints or color figure charges

- Immediate publication on acceptance

- Inclusion in PubMed, CAS, Scopus and Google Scholar

- Research which is freely available for redistribution

Submit your manuscript at www.biomedcentral.com/submit
C Biomed Central 